\section{La resignificación del término "producto" en el ámbito cultural}

Yoska Lázaro *

Resumen: El concepto de producto parece tener un significado negativo cuando entra en el mundo del arte. Éste prejuicio históricamente ha generado polémica entre artistas, repercutiendo negativamente al desarrollo y permanencia de los propios realizadores. Lo económico con lo artístico no sólo no es incompatible sino que es necesario. Ésta escisión debilita al propio arte. La concientización de éste hecho genera para el artista un cambio de panorama y de posibilidades. Éste cambio de paradigma supondría la apertura y profundización del campo artístico y, en consecuencia, una notable elevación de calidad del mismo.

Palabras claves: conflicto ético - la decisión del público - lo simbólico - panorama económico del teatrero - por "amor al arte" - potencia artística - producto cultural - teatro empresarial - temporadas.

[Resúmenes en inglés y portugués en la página 125]

${ }^{(*)}$ Egresado de la carrera de Dirección Teatral de la Escuela de Arte Dramático de Buenos Aires y como actor de la Escuela de Teatro de Buenos Aires de Raúl Serrano. Estudió también en el Sportivo Teatral, con Ricardo Bartís, y el Laboratorio de Teatro de William Layton de Madrid.

Comenzaremos por definir el concepto de producto. Tal significante se basa en las siguientes tres premisas:

1. Un producto es cualquier ofrecimiento que tiene la capacidad de satisfacer una necesidad o un deseo.

2. Un producto puede ser alguna de las siguientes diez ofertas básicas:

- Un objeto físico o bien tangible: por ejemplo, un auto, una prenda de vestir, un celular, etc.

- Un servicio: por ejemplo, una atención médica, la asesoría de un experto, el transporte que realiza un taxi, etc...

- Una persona: por ejemplo, un candidato a presidente o senador, un conferencista especializado en algún tema específico, etc... 
- Un lugar: por ejemplo, una isla paradisíaca para vacacionar, una ciudad tranquila para que los recién casados pasen su luna de miel, etc...

- Una organización: por ejemplo, una empresa, una fundación, un club de amigos, etc...

- Un evento: por ejemplo, el concierto de algún cantante famoso, un partido de fútbol, etc...

- Una experiencia: por ejemplo, un viaje de travesía por una selva virgen.

- Una información: por ejemplo, los datos acerca de cómo invertir en una determinada industria.

- Una idea: por ejemplo, un proyecto de inversión con alta probabilidad de lograr un alto retorno sobre la inversión.

- Una propiedad: por ejemplo, una casa de campo o de playa que se compra para habitarla en ciertos días del año.

3. Un producto es aquello que tiene la capacidad de:

- Atraer la atención

- Ser ofrecido para ser adquirido

- Ser susceptible de ser usado o consumido

En síntesis, el concepto de producto es el siguiente: "Cualquier ofrecimiento que tenga la capacidad de satisfacer una necesidad o un deseo, y que para ello, pueda atraer la atención del público objetivo para ser adquirido, usado o consumido. Un producto, puede ser un bien tangible, un servicio, una idea, una persona, un evento, una experiencia, un lugar, una organización, una información o una propiedad."

Es dificultoso introducir un término como producto en el campo del arte. Es delicado y sobre todo parece poco acertado o inadecuado a un mundo donde lo interior, lo simbólico, mas allá de la apariencia o lo banal, se manifiesta. ¡¿Producto?! Ś́, producto. ¡¿Una obra de teatro es un producto?!. ¡¿Cómo?! -gritan los puristas del arte y del buen hacer. Pues así es. Una obra de teatro es un producto. Como ya adelanté, esta aseveración tiene, mayor número de detractores que afines. Y ese es un motivo de por qué el término producto pareciera no encajar en el mundo de lo bello, de lo sensitivo. Pero la realidad del afuera de la escena o la creación es otra. En esa realidad impera la necesidad por lo factible, por lo concreto, por el comer y el vestir. Y el deseo del artista es que se puedan cubrir esas necesidades con su hacer. Es ahí, donde la distancia entre lo artístico y lo pragmático de la necesidad el día a día, han de pactar para encontrar un equilibrio. Y ese pacto, ese "cómo" se vuelve una de las incógnitas más difíciles de resolver por el hacedor. Por el que ansía, que no haya una coyuntura entre el deseo y lo concreto. En breve, volveremos a desarrollar este punto. Por ahora, seguiremos por aquí.

La historia del arte y del artista se debate, desde siempre, entre una dicotomía existencial: este termino producto. Parece, para algunos, que divide a los artistas en dos grupos: los que son atravesados por el arte y lo sitúan en un lugar casi sagrado donde se auto designan defensores puristas del "bien hacer"; y por otro lado están los "comerciantes". Estos últimos son personas que tratan a cualquier arte como objeto de venta e, insensibilizados, trafican con el mismo, como delincuentes artísticos o manipuladores de la buena intención de las expresiones de quienes están más allá del vil metal. Por ejemplo, la historia del teatro independiente argentino de los 70, vivió una situación análoga. Se enfrentaron dos 
posturas: aquellos que creían en un teatro político donde la importancia estaba en el mensaje, un mensaje que trasmitiera ciertos ideales al espectador. Al otro lado, posicionados así por estos primeros, quienes empezaron a pensar que el arte tenía que cuidar su forma y su estética dado que era consumido por un publico que podría obtener una pieza artística mas allá de un mensaje político panfletario. Y comenzaron a abrir escuelas de formación del actor, mal vistas por quienes hacían con el teatro su revolución.

Otro ejemplo de una situación de similar conflicto "ético" fue la aparición de la televisión. Considerar que uno podría pensar en la remuneración por encima del hecho mismo, tildaba al actor de "vendido". Éste nuevo medio de comunicación proporcionaba ingresos y generaba visibilidad a los artistas. “¿Qué hacer? ¿Comer o no comer, he ahí la cuestión? ¿Sufrir los golpes de la insultante hambre, o tomar las armas y hacer un personajito en TV y engordar un poco?". Pero, ¿ es así? Eso solo lo saben los que lo vivieron y no fue para todos igual. Ésta broma, poco lúcida, pretende ironizar sobre los extremos. Extremos heredados por un determinado hacer que no contiene las necesidades del hacedor, quién pareciera tener que vivir en condiciones ideales donde las mismas están más que cubiertas y puede dedicarse plenamente a un arte sin fines de lucro, que no necesita del dinero para subsistir. Creo, luego existo.

Por semana se estrenan unas doce o catorce obras, representándose un total superior a 400 espectáculos por semana. Todo esto repartido entre los distintos panoramas teatrales que conviven en la ciudad: teatro oficial, comercial e independiente-off. Esta proliferación de salas es un acontecimiento muy admirado en el resto del mundo. La potencia artística de Buenos Aires es comparable a Berlín, Londres o Broadway. La capital porteña es una de las más importantes de mundo, respecto a la producción teatral. Ello se debe a la cantidad de empresarios, productores, dramaturgos, directores, iluminadores, bailarines, músicos y público que desarrollan su actividad fervientemente provocando y ocupando las salas porteñas, generando un movimiento cultural envidiable. Es muy importante destacar el último actante marcado en la enumeración de culpables de dicho movimiento cultural: el público. Sin éste componente, el teatro no existe. Y Buenos Aires tiene un interesado receptor. Para que una actividad así se sostenga, necesita de quien lo consuma. Con mayor o menos afluencia, los espectáculos tienen una cuota importante de espectadores. Siendo el teatro independiente-off el mayor receptor de consumidores en Buenos Aires. Pero esto no es todo, si Buenos Aires se destaca por su envidiable actividad, Argentina posee plazas teatrales importantes en su interior como son Mar del Plata, Villa Carlos Paz (Córdoba) y San Luis. Estas ciudades tienen la característica de acoger espectáculos en periodos vacacionales (tanto en verano como en vacaciones de invierno) con una excelente ocupación de sala por parte de miles de turistas que toman la actividad teatral como parte de su rutina en su descanso laboral o estudiantil.

Éste hecho supone que, si bien en la capital merman los espectáculos en vacaciones veraniegas (no así en las de invierno), la producción teatral se federaliza, generando, no sólo que el público del interior pueda acceder a obras que no podrían ver por estar instaladas en la Capital, sino que se preparan obras especialmente, ya sea de los lugareños como de otros puntos de Argentina que van a hacer "la temporada".

A ésta extraordinaria realización artística argentina, se le añade un fenómeno emergente cada vez con más fuerza: funciones teatrales durante la semana. Esta experiencia, anterior- 
mente inaudita, encontró vivencias más que significativas en diversos espectáculos, siendo uno de los más destacables la obra Open House de Daniel Veronese que durante tres años se representaba los lunes. Actualmente, la cantidad de obras que encuentran su lugar en días "poco teatrales" es cada vez mayor. Los teatros de mayor relevancia abren sus puertas de domingo a domingo, sabiendo que hay un publico, antes reticente, que encuentra en esta alternativa una excelente salida para hacer su semana mas llevadera.

Aun así, La cantidad de obras presentes, son un porcentaje mínimo de los intentos por ser, de muchos espectáculos, que quedan en un intento fallido. Y de las que hay, un porcentaje aún menor tienen una calidad artística destacable. A su vez, estas obras de cierta altura, en el mayor de los casos, pasarán desapercibida o casi como por efecto de la peste, morirán al cabo de dos o tres meses. Todo esto tiene un por qué: en Buenos Aires se produce muchísimo y dentro de esa enorme cantidad, unos muchos hacen bastante mal, significando un desesperanzador final ante las enormes ganas y trabajo invertido. Este mal hacer apunta a una ausencia de conciencia de la producción. Son producciones que carecen de planificación, análisis o previsión alguna que pueda fortalecer e incrementar sus posibilidades vitales.

La producción ha de nutrir al teatrero, al artista escénico, de herramientas que le permitan realizar con garantías, disminuyendo el margen de riesgo para hacer de su trabajo, esfuerzo y dedicación una experiencia exitosa en lo posible. Uno de los grandes retos del docente teatral es trasladar el interés por el análisis de lo que se desea hacer y su por qué; así como hacer entender que una planificación organizada, minuciosa y previsora, es un punto de suma importancia a la hora de pretender arribar a buen puerto con un proyecto. Un proyecto que pueda tener cierta permanencia en cartel y que pueda suponer para los actantes, como marcamos antes, una retribución satisfactoria en lo artístico, lo personal y lo económico. ¡Lo económico! He aquí otro término u otra variable de fácil sensibilización para el artista como ya marqué antes. ¿Y por qué? ¿Por qué el teatrero ve mal lo relativo a lo económico? La historia del teatro, ha perdido a muchos talentos que encontraron en otro tipo de trabajo, la estabilidad económica necesaria para desarrollarse personal y familiarmente. Terminado por apartarlo de lo que fue su arte, para que quede denostado en hobbie. ¿Y pretender cobrar por el hacer teatral es malo? Malo es ver como gente que debería vivir sobre las tablas, vende seguros de vida para bancos internacionales. Lo teatral y el dinero no son antagónicos. Al revés, se necesitan para un más y mejor. Cuando el dinero entra en el teatro o el formato que se maneja tiene una fuerte llegada al público, el término "comercial" trata de desvalorizar lo hecho y el hecho. Hay un buen teatro comercial/empresarial con buena producción artística. Claro que lo hay.

Y volvemos al término producto. ¿Qué importancia tiene? Pasa por un posicionamiento frente al hacer teatral. Según como uno hace, se dirige a un lugar u otro; tiene un destino $u$ otro, pese a que parezca exagerado, o quizá un ejercicio de autoayuda. Y digo esto, porque la consideración de producto, conlleva un consumidor. Así que según el consumidor, así será el producto. ¡Usted, elija a quien va dirigido, y actúe en consecuencia! ¿Tan fácil o tan simple? Pues sí. Yo sostengo una concepción de producto consumible. Es ahí, donde considero que el mercado terminará discriminando entre el hacedor teatral y el practicante. Teniendo una diferencia entre ambos, correspondiente a la calidad del hacer y al que se prepara para poder concretar su actividad con cierto nivel. 
¿Quién decide esa calidad? Se confía, con cierta inocencia, en el propio espectador y en los compañeros del medio teatral. ¿Ellos van a decir qué esta bien y que está mal? Con el tiempo, van quedando aquellos que hacen con trabajo, lo que sueñan, y lo concretan. No puedo dejar de reconocer cierta idealidad en el receptor, pero confío en que el hacer a conciencia y con profesionalidad, ira exquisitando el paladar emocional del público.

A donde apunto es a una reflexión, como decía antes, factible de rebatir, que a una certeza. Pero creo que es un punto importante a considerar. Pues hay algo en todo hacer que puede mejorarse. Quizá entre en colisión con posturas “éticas” de muchos, y/o , pueda parecer ilusoria o mezquina. Puede ser. Sé que esta reflexión compartida, tiene como origen la experiencia personal. En mi persona, confluyen el creador y el organizador, planificador y gestor. Ambas áreas, la artística y técnica, están presentes en mis realizaciones. Cuando dirijo o escribo, pienso en producción, también. En practicidad, en solvencia. Es desde ahí que trato de reflexionar sobre el hacer teatral pensando que en el origen del proyecto y su forma esta el punto clave.

En el hacer teatral, soy testigo de la experiencia de muchos compañeros teatreros que me llevó a considerar cuatro tipos de panoramas personales en los que pueden englobarse a los distintos artistas escénicos frente al hacer teatral.

Las distintas situaciones personales sitúan cuatro panoramas:

1. Los que viven (a veces mejor, a veces peor) de su actividad teatral. Suele ser gente que ha podido encontrarle Teniendo en cuenta que para ello, comúnmente, son múltiples facetas las que han de desarrollar para poder cubrir las necesidades personales y familiares. Siendo la docencia, el recurso de subsistencia económico mas utilizado.

2. Al que su hacer teatral, no le facilita la solvencia económica y ha de complementarlo con un trabajo "convencional" que le permite continuar con su actividad artística. Éste grupo, anhela poder obtener una mejor posibilidad económica y busca con su trabajo artístico, la forma de conseguirlo una vez que se ha tomado la decisión. No siempre se toma. La necesidad de una garantía económica la dificulta .

3. Quienes toman lo teatral como un hobby que permite expresar sus inquietudes y con el que se desarrollan personalmente. En éste grupo, no hay conflicto inicialmente y es clara la posición tomada respecto al hecho artístico.

4. Los que tras desear vivir de su pasión y no conseguirlo, abandonan. Dejan el teatro y se reincorporan al "común de la sociedad", según se piensa. Obtienen un trabajo que les permite llevar una vida familiarmente organizada y olvidan lo que una vez quisieron ser. Para un teatrero que observa, sin duda, es el caso más doloroso.

Éste ensayo pretende hacer reflexionar, sobre todo, a los grupos 2 y 4 . Y considerar nuestra posición para, con suerte y voluntad, podamos ver qué, cómo y por dónde. Y así, cada uno puedo elegir a qué grupo quiere pertenecer.

Todo esta armado, en ésta sociedad, para que uno tenga un trabajo convencional, aceptable, carente de fantasías que no respondan a lo económico, valor principal rescatable del ser humano (¿?). ¿Así que no vamos a fijarnos en lo económico?

Cuando marco la importancia, quizá evidente para algunos, del público, estoy apuntando a reflexionar sobre el hacer. Un hacer que se reformula cuando esta variable está presente. 
Suponiendo, que la concepción de un "algo" destinado a un receptor legitimado, conllevarán una concientización y revisión en el hacer.

Esta concientización podría alivianar el reducto de obras auto satisfactorias que podrían manifestar debilidades propias de la actividad, ausente del registro del otro que el sistema teatral permite exhibir en su gigantesca maquinaria y que, mas allá de ser festejada esa posibilidad y el emprendimiento de los hacedores, no están listas para mostrarse "profesionalmente" al público en general. Siendo la ausencia de trabajo, planificación, reflexión y hacer a conciencia el motivo de la ausencia de un mínimo de calidad que, mas allá de la insatisfacción del público presente, significará el fracaso del proyecto y del grupo realizador cuando su permanencia se haga insostenible y las frustraciones tanto artísticas como económicas se hagan presentes, conllevando en ocasiones la insatisfacción e incluso el abandono de la actividad por considerarse insustentable o desproporcionada la resultante del cruce de las variables costo/beneficio. Esto siempre refiriéndonos a un teatro que busca la presentación pública con costos de entradas propios de producciones profesionales. En el caso del amateurismo o el teatro cuya finalidad no contiene las variables de cobrar entrada para un beneficio y no se pretende coquetear con el profesionalismo todo hacer es mas que beneficioso y alentable. Siendo su rédito siempre mas que positivo para el hacedor y el receptor.

Entonces, ¿se supone que aceptar el término producto en lo teatral es la solución? No. No lo es. Es una toma de conciencia. Es un principio. Es una posibilidad. Aquel que hace considerando que el espectáculo teatral es para el público, dejando de lado como única finalidad una propuesta escénicas de autosatisfacción, y tenga un hacer reflexivo, obtendrá mayor calidad de espectáculo, un favorable "boca a boca", y en consecuencia, una llegada a mayor cantidad de gente, según se vaya realizando obras. Desembocando en poder estar, cada vez más, dedicado a su hacer para obtener de su pasión o vocación su modo de vida. Esto, no significa, no hacer lo que uno desea o perder libertad de creación; significa conciencia en un hacer, en busca de una mejora en la calidad artística y en la redituabilidad económica del espectáculo.

¿Pero quién dice que esto sea la solución? No es una solución de nada. Como decíamos antes es una posibilidad, una forma de entender cierto hacer y de revisar lo hecho. Se invita a ver los números de las producciones hechas y de las que son sustentables o aceptables artísticamente. ¿Y quién esta en condiciones de juzgar los aceptable artísticamente? ¡El público! Con esto no se dice que no sea bueno ese hacer indiscriminado de la escena porteña, pero podría ser mucho mejor si se reflexionara un poco más. Quizá el impulso sea más fuerte que la razón, pero la decepción de quien no prevé o planifica puede conllevar el abandono de la actividad. Y seria una pena.

Es ahí donde me inquieta esa postura, descreída, descalificadora, inocente, frente a la búsqueda de la redituabilidad. ¿De qué vivimos si no? "Por amor al arte" no se vive. No se puede sostener. Es difícil trabajar en teatro cuando nueve o diez horas antes, estuviste en el trabajo que te da de comer.

Se puede considerar que éste concepto mercantilista del teatro, puede ser una amenaza para la creación, para el deseo. A eso se puede decir que los intereses económicos siempre van a encontrarse en todo movimiento prolífero. 
Pero insisto en que confío en que será sin duda el propio medio artístico y el público soberano empapado de posibilidades teatrales y acercado al espacio físico por las posibilidades que idealmente deberían permitir al espectador el acceso al teatro mismo (políticas culturales), quienes serian filtro del buen gusto por el ver y el hacer. El estrecho triangulo: obra, artista, espectador; la aceptación de lo artístico como producto consumible y rentable para el hacedor; la auto revisión del hacer y la gran calidad de los artistas argentinos, significará, ingenuamente o no, un salto cualitativo de la poética propia, beneficiando, directamente, al entorno artístico en que productor y producto se desenvuelven.

Por tanto, la productiva, admirada e imitada Buenos Aires, podría alcanzar niveles artísticos difícilmente igualados en otros países. Dado que a las dificultades económicas, Argentina, ha respondido con trabajo y talento. ¿Qué pasaría si toda esa materia prima, esos genuinos recursos, estuvieran mejor direccionados, contenidos, encauzados? No lo sé, pero no querría perderme ese torrente espectacular.

Summary: Product concept seems to have a negative meaning when he enters the world of art. This prejudice has historically generated controversy among artists, negatively impacting the development and retention of filmmakers. Economics with art is not only compatible but necessary. This split weakens the art itself. Awareness of this fact for the artist generates a change of outlook and possibilities. This paradigm shift would mean the opening and deepening the of the artistic field and, consequently, a significant rise in quality.

Keywords: artistic power - business theater - cultural product - economic outlook of the theater maker - ethical conflict - for the loving to art - seasons - the decision of the audience - the symbolic.

Resumo: O conceito de produto parece ter um significado negativo quando entra no mundo da arte. Este prejuízo historicamente gerou polemica entre artistas, repercutindo negativamente ao desenvolvimento y permanência dos próprios realizadores. O econômico com o artístico não é somente compatível senão que é necessário. Esta divisão debilita à própria arte. A conscientização deste desmembramento gera para o artista uma troca de panorama e de possibilidades. Esta mudança de paradigma supõe a apertura e aprofundamento do campo artístico e, em conseqüência, uma notável elevação da sua qualidade.

Palavras chave: conflito ético - decisão do público - o simbólico - panorama econômico do teatro - por amor ao arte - potencia artística - produto cultural - teatro empresarial temporadas. 